\title{
Intensos encontros: Michel Foucault, Judith Butler, Paul B. Preciado e a teoria queer
}

\author{
Kris Herik de Oliveira' (D) 0000-0002-0530-2513 \\ 'Universidade Estadual de Campinas, Instituto de Filosofia e Ciências Humanas, \\ Campinas, SP, Brasil. 13083-896 -scpgcsoc@unicamp.br
}

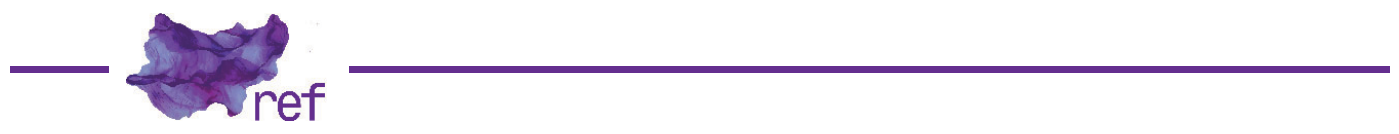

Resumo: A teoria queer é apresentada neste artigo como um conjunto de encontros entre pensamentos em constante reinvenção. Derivam desses diálogos tessituras de conceitos e operações analíticas com disposição política, cujas forças residem em suas habilidades de afrouxar ou até mesmo desatar os nós de verdades cis-heterocentradas, especialmente, no que diz respeito a corpos, gêneros e sexualidades. Nesse sentido, realizo uma revisão das ideias principais em três obras consideradas centrais à epistemologia queer: História da sexualidade 1: a vontade de saber, de Michel Foucault; Problemas de gênero: feminismo e subversão da identidade, de Judith Butler; e Testo yonqui, de Paul $B$. Preciado. No tocar dessas movimentações, menciono as aproximações e os distanciamentos entre as propostas, bem como os seus efeitos em leituras brasileiras.

Palavras-chave: Teoria queer; Michel Foucault; Judith Butler; Paul B. Preciado; revisão da literatura.

Intense Encounters: Michel Foucault, Judith Butler, Paul B. Preciado, and the Queer Theory Abstract: This article presents the Queer Theory as encounters between thoughts in constant reinvention. Germinate of these dialogues weavings of concepts and analytical operations with political disposition, whose forces resides in their abilities to loosen or even untie the nodes of cis-heterocentered truths, especially, with regard to bodies, genders and sexualities. In this sense, I review three works considered central to queer epistemology: The history of sexuality 1: the will to knowledge, by Michel Foucault; Gender trouble: feminism and the subversion of identity, by Judith Butler; and Testo junkie: sex, drugs, and biopolitics in the pharmacopornographic era, by Paul B. Preciado. In these movements, I mention the approaches and distances between the proposals, as well as mentioning their effects in Brazilian readings.

Keywords: Queer theory; Michel Foucault; Judith Butler; Paul B. Preciado; literature review.

\section{Introduçāo}

Um encontro só se faz possível por meio de deslocamentos. Corpos, rios, vasos sanguíneos, linhas, moléculas, microrganismos, energias, pensamentos, tudo o que está em movimento pode render encontros. Esses encontros podem ser imprevisíveis, gerar colisões, curtos-circuitos, levar a confluências ou promover novas existências. As intensidades mobilizadas por um encontro produzem experiências complexas, que são capazes de inaugurar possibilidades de transformação. Por isso, como coloca o filósofo Luiz Orlandi (2018), os encontros são produtores de devires.

Neste artigo de revisão, a teoria queer é apresentada como um conjunto de encontros entre pensamentos em constante reinvenção. Derivam desses encontros tessituras de conceitos e operações analíticas com disposição política, cujas forças residem em suas habilidades de afrouxar ou até mesmo desatar os nós de verdades cis-heterocentradas, especialmente, no que diz respeito a corpos, gêneros e sexualidades. Portanto, seguindo Guacira Lopes Louro (2012), pioneira dos estudos queer no Brasil, não recorro à ideia de teoria no sentido de sistematização ou estrutura. 
Como fruto das discussões provocadas pelo feminismo, pelo pós-estruturalismo, pelos estudos culturais, por mobilizações étnico-raciais, pelo movimento LGBTQIA+ e em meio à epidemia de HIV/aids, o queer ' foi pensado com propósito teórico em uma conferência realizada por Teresa De Lauretis, na Universidade da Califórnia, Santa Cruz (EUA), em fevereiro de 1990. Na conferência, De Lauretis (1991) buscou distanciar-se do sentido queer utilizado pelo grupo político Queer Nation. A sua proposta ali era pensar as sexualidades consideradas dissidentes e patológicas, não como minoria e opostas à heterossexualidade (reprodutiva e institucionalizada, portanto, naturalizada), mas estudar a sua relação cruzada com outras categorias analíticas, como gênero, raça, geração e nacionalidade. Em outras palavras, De Lauretis problematizou dois modelos até então pensados pelos gay and lesbian studies, ${ }^{2}$ o patológico e o do pluralismo, que ainda promoviam políticas de identidade e atestavam um estilo de vida opcional.

De acordo com De Lauretis (1991), a teoria queer teria uma dupla função: evidenciar as produções discursivas e conceitualizá-las, além de realizar um trabalho crítico de desconstrução dos discursos dos próprios pesquisadores de gênero e sexualidade, dando voz aos silêncios que foram construídos. Nesses empreendimentos, os estudos queer também teriam como objetivo cruzar as fronteiras disciplinares em aspectos teóricos e metodológicos ao estabelecer diálogos entre ciência, literatura e arte. No campo político, caberia ainda buscar o equilíbrio entre igualdade e diferença na esfera pública.

Para Halperin (2003), a teoria queer apostou no tom provocador. A seu ver, a apresentação de Teresa De Lauretis possuía três aspectos centrais. Primeiramente, buscou desestabilizar a homogeneização dos estudos gays e lésbicos, isto é, questionar o consenso de que homossexuais e lésbicas compartilhavam experiências comuns e que por isso os estudos dessas 'identidades' deveriam caminhar juntos. Em segundo lugar, desafiou as ciências sociais a se abrirem para possibilidades de reflexão de ordem teórica mais ampla ao introduzir a problemática das múltiplas diferenças, com uma abordagem distinta aos estudos hegemônicos de modelos gays/lésbicos de classe média, masculinos e brancos. Por fim, formulou uma teoria de problematização constante aos fundamentos heterossexuais das teorias vigentes, chamando atenção para os desejos e prazeres estranhos e perversos. Dessa maneira, a teoria queer atenderia às lacunas científicas e à demanda sociopolítica evidente desde a década de 1960.

Com essa proposta, a teoria queer foi efetiva em importantes aspectos: problematizou as promessas teóricas dos estudos gays e lésbicos; viabilizou o realinhamento entre as questões de sexualidade e gênero; abriu possibilidades para o florescimento de estudos transgêneros; prosseguiu com a tarefa (iniciada muito antes nos estudos gays e lésbicos) de separar a crítica de gênero e sexualidade das noções cristalizadas de identidades lésbicas e homossexuais; apoiou as expressões não normativas de gênero e sexualidade, incentivando a resistência teórica e política à normalização; subscreveu uma série de críticas teóricas cruciais sobre violências; e, ao absorver a crítica decolonial, redefiniu a construção da história lésbica, gay, bissexual e transgênero. Além disso, outra grande potencialidade dos estudos queer estaria na sua capacidade de problematização e reinvenção constante (David CÓRDOBA; Javier SÁEZ; Paco VIDARTE, 2007; HALPERIN, 2003).

O meu propósito aqui não é reconstruir uma cronologia exaustiva da insurreição política, cultural, artística e intelectual queer. ${ }^{3}$ Este artigo trilha outros caminhos. Nas páginas que seguem, busco realizar uma revisão das ideias principais em três obras consideradas centrais à epistemologia queer: História da sexualidade 1: a vontade de saber, de Michel Foucault; Problemas de gênero: feminismo e subversão da identidade, de Judith Butler; e Testo yonqui, de Paul B. Preciado. As obras em questão foram selecionadas levando em consideração que a entrada do queer na via acadêmica se deu por meio delas, conforme sublinha Larissa Pelúcio (2014). Como as ideias desses autores se aproximam e se distanciam? Quais são as suas principais contribuições conceituais e analíticas à teoria queer? De que maneira as pesquisas brasileiras têm lido esses saberes?

Não se trata, contudo, de fixar a esses autores uma 'identidade queer', uma vez que, dentre eles, Preciado é o único que leva em seus trabalhos a crítica queer às últimas consequências. Foucault não é considerado um teórico queer em sentido estrito, mas um dos semeadores das bases teórico-metodológicas por intermédio das leituras de Butler. A filósofa, entretanto, não nega

1 Em um primeiro momento, o termo inglês queer era usado em referência a algo ou alguém estranho. Depois, queer foi utilizado com conotação negativa e agressiva contra os corpos que transgrediam as normas de gênero e sexualidade. Tratava-se de um xingamento, pensando no contexto brasileiro, como 'bicha', 'sapatão', 'marica', 'traveco'. Na segunda metade do século passado, o queer foi ressignificado gradualmente, impulsionado pelo ativismo LGBTQIA+ em contraposição ao imaginário de anormalidade.

2 Nos anos de 1970/1980, ganhou expressão uma importante literatura sócio-histórica voltada, a princípio, às singularidades de uma 'cultura homossexual masculina'. Os enfoques dessas abordagens versavam sobre a construção social da homossexualidade, comportamentos sexuais e estilos de vida. Em seguida, estudos voltados às experiências lésbicas ganharam atenção, bem como aqueles interessados nas experiências comuns entre gays e lésbicas. Esse conjunto de investigações ficou conhecido como gay and lesbian studies (estudos gays e lésbicos). Para uma leitura crítica dessa linha de pesquisas ver De Lauretis (1991) e David Halperin (2003).

${ }^{3}$ Para isso, sugiro a leitura do livro organizado por Córdoba, Sáez e Vidarte (2007), assim como o de Richard Miskolci (2012). 
nem recusa o termo, mas pondera que toda categoria identitária deve ser pensada e os seus limites apontados. As entrevistas com Paul B. Preciado (Jesús CARRILLO, 2007) e Judith Butler (Sara AHMED, 2017) são esclarecedoras a esse respeito.

Estudos dedicados à revisão das bases teóricas e metodológicas queer são realizados há pelo menos vinte anos. No artigo seminal intitulado Teoria queer: uma política pósidentitária para a educação, Louro (2001) destaca algumas pistas importantes ao revisitar as formulações de Foucault e Butler: o caráter discursivo da sexualidade; a crítica à normalização, à universalização e às políticas da identidade; a desconstrução enquanto operação metodológica; e a performatividade de gênero para se referir à fabricação de corpos e sujeitos. Desde então, Preciado e outras importantes referências ${ }^{4}$ foram recuperadas para se falar de teoria queer, assim como críticas foram direcionadas às aplicações pouco ou nada reflexivas dos conhecimentos do 'norte' em pesquisas brasileiras (MISKOLCl, 2014; PELÚCIO, 2014; Pedro Paulo PEREIRA, 2012).

As releituras, entretanto, têm priorizado reconstruções das bases sócio-históricas da teoria em vez de arriscar composições que tornem mais acessíveis os conceitos e as operações analíticas queer. Foucault, Butler e Preciado são filósofos de leitura intrincada, o que pode levar a compreensões equivocadas de suas ideias. Ademais, as articulações entre eles ainda são pouco realizadas. Portanto, estimular diálogos entre os autores pode oferecer contribuições que ajudem a pensar criticamente a produção de corpos, gêneros e sexualidades na atualidade e, de maneira mais ampla, o desenvolvimento teórico queer.

\section{Michel Foucault \\ O dispositivo da sexualidade}

Como passamos a nos reconhecer como sujeitos de uma sexualidade em detrimento de outras possibilidades? Esse é o problema central perseguido por Michel Foucault em História da sexualidade 1: a vontade de saber, obra publicada originalmente na França, em 1976. Tratase de uma investigação que transcende a reunião de fatos ordenados cronologicamente em torno das condutas sexuais e de sua repressão, de modo a tornar visível a complexa malha de saber-poder que compõe a sexualidade humana. Ainda que o recorte empírico tenha se concentrado na transição da idade clássica (séculos XVII-XVIII) à modernidade (séculos XIX-XX) em contexto europeu, a afinada contribuição de Foucault inspirou e estimulou uma intensa produção acadêmica sobre a temática da sexualidade nas décadas subsequentes.

Ao operar com uma "genealogia da sexualidade" - conceito ancorado na "genealogia da moral", de Nietzsche -, o filósofo se voltou para os jogos de verdade sobre a sexualidade produzidos discursivamente por múltiplas instituições ao longo da história. Dito de outro modo, vemos o seu interesse pelos processos que conferem legitimidade a um discurso, coroando uma verdade, e também pela maneira que outros discursos não foram legitimados ou foram abafados. Tendo em vista a possibilidade de analisar tais aspectos não necessariamente contínuos, no primeiro volume de seu projeto sobre a história da sexualidade ocidental, ${ }^{5}$ pretendeu "determinar, em seu funcionamento e em suas razões de ser, o regime de poder-saber-prazer que sustenta, entre nós, o discurso sobre a sexualidade humana" (FOUCAULT, 1999a, p. 16).

Segundo Butler (2003), Foucault preocupou-se em evidenciar como os discursos ganham materialidade e são legitimados na relação com o sistema econômico, o campo político e outras distintas instituições. A genealogia não busca as origens das categorias, mas atenta para as políticas de identidade que são, na verdade, "efeitos de instituições, práticas e discursos cujos pontos de origem são múltiplos e difusos" (BUTLER, 2003, p. 10, grifo da autora). É nessa teia que aspectos discursivos (tudo o que em uma sociedade funciona como obrigação, os comportamentos aprendidos) e pré-discursivos (anterior às práticas, à cultura, como o corpo) se emaranham. Conjuntamente, são fabricados efeitos de verdade, isto é, atos pós-discursivos (as políticas de identidade) que atuam como mecanismos de poder.

Para melhor compreender a pesquisa em questão, é importante sublinhar as quatro "prescrições de prudência" consideradas por Foucault (no lugar de metodologia, ele prefere empregar esses termos). A primeira, "regra da imanência": considerar que a sexualidade vai além de um conhecimento específico, pois envolve artefatos econômicos ou ideológicos como produtores de mecanismos de proibição. Sendo assim, convém apreender os focos locais de poder-saber: confissões, interrogatórios, vigias do corpo etc. A segunda, "regra das variações contínuas": procurar o jogo de forças e suas modificações em vez de buscar quem tem o poder na ordem da sexualidade (os homens, os adultos, os pais, os médicos) e quem é privado de poder (as mulheres, os adolescentes, as crianças, os doentes etc.), tampouco quem tem o direito

\footnotetext{
${ }^{4}$ São alguns nomes: Eve Sedgwick, David Halperin, Guy Hocquenghem, Monique Wittig, Adrianne Rich, Gayle Rubin, Gilles Deleuze e Félix Guattari.

${ }^{5}$ Inicialmente, Foucault esperava apresentar seis volumes da história da sexualidade, embora acreditasse não chegar a tanto. No entanto, em vida, publicou três: A vontade de saber, em 1976, O uso dos prazeres, em 1984, e 0 cuidado de si, em 1984. Recentemente, houve a publicação de um volume póstumo: As confissões da carne, em 2018.
} 
de saber sobre a sexualidade, ou é mantido à força na ignorância. A terceira, "regra do duplo condicionamento": Olhar para o local e também para as estratégias globais. A quarta, "regra da polivalência tática dos discursos": é no discurso (enquanto segmento descontínuo, múltiplo, disforme e instável) que se articulam poder e saber estrategicamente, pois, o discurso veicula o poder e reforça-o. Esse procedimento metodológico empregado em História da sexualidade 1 também foi experimentado em Vigiar e punir: nascimento da prisão (FOUCAULT, 1999b) para o estudo das tecnologias de vigilância e punição. Desse modo, à medida que Foucault se volta à capilaridade da sexualidade, deixa valiosas pistas metodológicas para o que viria a se entender por teoria queer.

Desconfiando da hipótese repressiva, o filósofo observou que no início da modernidade a sexualidade foi submetida a um processo crescente de incitação e explosão discursiva. Este não se trata de um argumento que rejeita integralmente a repressão da sexualidade, mas que busca examinar as ações microfísicas, que se encontram nas atuações e estratégias das instituições. Os documentos analisados evidenciaram restrições de vocabulário e a censura de expressões. Contudo, as expressões do desejo escaparam para a literatura e as artes. E, embora existente em períodos precedentes, a colocação do sexo (como relação sexual) em discurso foi então normatizada; impôs-se um imperativo "não somente confessar os atos contrários à lei, mas procurar fazer de seu desejo, de todo o seu desejo, um discurso" (FOUCAULT, 1999a, p. 24). Assim, esse discurso configurou-se como "um dispositivo bem diferente da lei: mesmo que se apoie localmente em procedimentos de interdição, ele assegura, através de uma rede de mecanismos entrecruzados, a proliferação de prazeres específicos e a multiplicação de sexualidades disparatadas" (FOUCAULT, 1999a, p. 48).

Nesse sentido, Foucault apresenta os quatro braços de saber-poder-prazer articulados na modernidade: a gestão da sexualidade das crianças; a especificação das sexualidades periféricas; o prazer-poder da vigilância médica, pedagógica, familiar, social, legal, canônica e confessional; e os dispositivos de saturação sexual com a redução da sexualidade ao casal heterossexual legítimo e a proliferação de outras sexualidades. Então, por meio dessas ações de caráter produtivo e regulador, prazer e poder se entrelaçaram aos processos de subjetivação e sujeição modernos.

Nas palavras do filósofo,

sexualidade é o nome que se pode dar a um dispositivo histórico: não à realidade subterrânea que se apreende com dificuldade, mas à grande rede da superfície em que a estimulação dos corpos, a intensificação dos prazeres, a incitação ao discurso, a formação dos conhecimentos, o reforço dos controles e das resistências, encadeiam-se uns aos outros, segundo algumas grandes estratégias de saber e de poder (FOUCAULT, 1999a, p. 100).

Um dispositivo, portanto, possui natureza estratégica, a qual se liga aos jogos de poder, e também aos limites de saber que dele nascem e o orientam. O dispositivo da sexualidade, tão presente em nossas vidas na atualidade, sublinha o autor, teria se configurado a partir do século XVIII. A sua ação extensiva (além da lei) se deu por meio de técnicas móveis, polimorfas e conjunturais de poder. De um lado, houve a valorização e intensificação do discurso considerado indecente; de outro, uma "polícia dos enunciados", dos comportamentos, dos locais onde se pode falar de sexo e em quais situações. O objetivo desse dispositivo foi penetrar nos corpos, controlar os prazeres, as sensações e as populações.

Para Foucault, o sexo (ato sexual) foi um meio necessário do dispositivo da sexualidade porque também foi moldado através dele. No decorrer da história, os debates e estudos científicos sobre o seu princípio, a sua falta, a sua presença, seu excesso, sua função e o seu instinto foram impulsionados pelas histerias, pelo onanismo, pelo fetichismo e pelo coito interrompido. Aos poucos, tantas linhas de saber-poder-prazer formaram uma teoria geral do sexo. Dessa maneira, o dispositivo da sexualidade diluiu qualquer concepção puramente biológica do sexo.

Em sua perspectiva, através do controle técnico-científico da sexualidade, a sociedade ocidental moderna operou uma scientia sexualis, pois, ao buscar dizer a verdade sobre o sexo, desenvolveu um conjunto de procedimentos ordenados em função de uma forma de poder-saber ao mesmo tempo que se opôs rigorosamente à arte e à religião. O resultado dessas ações foi a criação de uma ciência-confissão repleta de rituais em busca da produção de verdade. A confissão da sexualidade permeou as formas científicas do século XIX através de cinco técnicas: de um "fazer falar" codificado pela clínica; do sexo como causa de tudo e de nada; articulando coerção de uma confissão difícil a uma prática cientifica; do método da interpretação (a sexualidade como algo a ser interpretado); e da medicalização dos efeitos da confissão. Assim, "através desse dispositivo, pôde aparecer algo como a 'sexualidade' enquanto verdade do sexo e de seus prazeres" (FOUCAULT, 1999a, p. 67). Com efeito, os controles sociais que se desenvolveram na modernidade e penetraram na sexualidade passaram a ditar a relação entre pais e filhos, casais, professor e aluno, médico e paciente, juiz e réu etc. 
Não por acaso, Foucault relata que, no século XIX, sexualidade e doença mental se fundiram. As formações discursivas envolvendo saber, poder e prazer criaram todo o vocabulário de abominação, conduzindo às condenações jurídicas, a "irregularidade sexual" foi anexada à doença mental, foi definida a norma do desenvolvimento sexual em cada etapa da vida (da infância à velhice) e seus desvios possíveis foram caracterizados. Coube aos tribunais condenar tanto a infidelidade quanto os 'comportamentos desviantes' da sexualidade. Como 'cura' aos escapes à norma, foram definidos e organizados controles pedagógicos e tratamentos médicos. A partir disso, a modernidade despontou como a era da heterogeneização e multiplicação das sexualidades e de suas perversões.

No que concerne ao dispositivo da sexualidade, Butler (2003) e Preciado (2008) concordam que as análises de Foucault foram criticamente precisas e, por vezes, excessivamente centradas na regulação dos corpos e prazeres por intermédio do sexo (órgão e prática sexual) construído discursivamente. Butler sustenta que pensar a sexualidade como efeito de práticas discursivas historicamente situadas confere possibilidades de desorganizar qualquer coerência 'natural' entre sexo, corpo e desejo. Além disso, as análises foucaultianas permitem questionar estratégias reguladoras que produzem os sujeitos a serem subjugados e, do mesmo modo, teorias da sexualidade que consideram culturalmente ininteligíveis outras sexualidades. No entanto, Butler coloca uma questão não identificada em Foucault (com base nos diários de Herculine Barbin, um hermafrodita francês do século XIX): se o sexo é a fonte das regulações da sexualidade, o que aconteceria com um corpo que não o possuísse ou o dispensasse? Ademais, ela destaca a limitação que estaria no aspecto coextensivo de sexualidade e poder proposta por Foucault, a qual refutaria qualquer possibilidade de emancipação. Nesse sentido, Preciado argumenta que o foco no funcionamento da sexualidade como dispositivo é insuficiente porque não direciona atenção necessária aos escapes dos aprisionamentos sociopolíticos. Afinal, toda prisão está sujeita às insurreições. Além disso, para o filósofo, as transformações tecnocientíficas mais recentes acerca da sexualidade passaram desapercebidas por Foucault.

Os apontamentos de Butler e Preciado são pertinentes porque dialogam com a prática autocrítica da teoria queer sobre os discursos dos próprios pesquisadores e pela defesa da valorização das diferenças. Mas isso não implica no abandono do conceito foucaultiano. Pelo contrário, o dispositivo da sexualidade contribuiu com a formulação de reflexões atualizadas e novas gramáticas.

A esse respeito, é possível mencionar a etnografia da prostituição masculina na cidade de São Paulo, realizada por Néstor Perlongher (1987), um dos percursores da teoria queer no Brasil (MISKOLCl, 2012; PELÚCIO, 2014). A partir de observações e entrevistas realizadas com michês e clientes, o antropólogo observou que o dispositivo da sexualidade - essa arquitetura de poder, com todas as suas estratégias e técnicas de exame, controle e punição sobre os prazeres dissidentes instaurou uma territorialidade "nas margens". Aos poucos, o desejo proibido e pago no "gueto gay" se territorializou em espaços estratégicos da cidade. Territórios não apenas no sentido espacial do termo, mas que também movimentavam questões morais, afetivas, econômicas, raciais, de gênero e violências. Nessas paisagens, de um lado, ganhou vitalidade a livre expressão do desejo com seus códigos e derivas. De outro, permaneceram os perigos envolvendo paixões, repressões policiais, assaltos e o medo da morte. Através desses fluxos de poder, afetos e devires, Perlongher nos conduz por uma tensão que se faz constante entre a normalização e o desejo.

\section{Uma era do biopoder}

As tecnologias de controle sobre a bíos - as formas de viver - levaram Foucault a aprofundar as reflexões experimentadas com o dispositivo da sexualidade. Então, entre discursos e práticas de governos, científicas, jurídicas, econômicas e cristãs, ele identificou expressivas transformações nas formas de poder para a gestão da vida e da morte.

Na idade clássica, o poder sobre a vida e a morte se concentrava nas mãos de um soberano, o mandatário das condições de vida, de castigos, execuções e guerras. Passado esse período, as guerras já não mais reclamavam um nome soberano a ser defendido, pois batalhas começaram a ser travadas em nome de populações inteiras como uma necessidade de viver. Durante a modernidade, Foucault (1999a, p. 130) observou que a soberania passou a ser exercida na esfera biológica, sobre a vida e seu desenrolar: "São mortos legitimamente aqueles que constituem uma espécie de perigo biológico para os outros. [...] Pode-se dizer que o velho direito de causar a morte ou deixar viver foi substituído por um poder de causar a vida ou devolver à morte" (grifos do autor). São exemplos desse direito de morte e poder sobre a vida as políticas étnicas e raciais que difundiram ideias evolucionistas de raça superior e raça inferior nos últimos dois séculos. As práticas discursivas higienistas serviram de fundamento para hierarquias sociais, estéticas corporais, múltiplas violências e genocídios. Esse perverso emaranhado entre biológico, social e político fornece as bases para o que o filósofo chamou de "era do biopoder". 
Com outras palavras, Foucault explica que a era do biopoder se desenvolveu na história em dois momentos. O primeiro teria despontado no século XVII sob uma "anátomo-política do corpo humano", a qual desdobrou-se na disciplinarização e no controle dos corpos por "técnicos do desejo", como juristas e psiquiatras. As técnicas e procedimentos aplicados almejavam a educação e a fabricação de corpos dóceis. O segundo momento emergiu no século XVIII através da "biopolítica", caracterizada pela regulação da população por intermédio de saberes específicos, como estatística, economia, medicina e demografia. Portanto, o conceito de biopoder incorpora as tecnologias de poder-saber identificadas no estudo da "sociedade disciplinar" (FOUCAULT, 1999b) - vigilância, classificação, hierarquização, punição e exame -, as quais também compõem o dispositivo da sexualidade.

Segundo o filósofo, desde que o biológico passou a refletir no político, e vice-versa, "o homem ocidental aprendeu pouco a pouco o que é ser uma espécie viva num mundo vivo, ter um corpo, condições de existência, probabilidade de vida, saúde individual e coletiva, forças que se podem modificar, e um espaço em que se pode reparti-las de modo ótimo" (FOUCAULT, 1999a, p. 134).

Tanto o sistema capitalista quanto o jurídico foram nutridos ao mesmo tempo que alimentaram essa nova era. O biopoder foi indispensável para o desenvolvimento do capitalismo ao garantir a sujeição dos corpos e das populações aos processos econômicos. Aliado a esse propósito, o sistema jurídico ganhou maior importância. Não coube mais à soberania matar ou decapitar, mas sim atribuir aos vivos um nível de valor e utilidade. Por isso, qualificar, medir, avaliar e hierarquizar se fez importante. Nesse contexto, a instituição jurídica se articulou cada vez mais às instituições de intuito regulador, como as médicas, administrativas e de ensino. Essa "sociedade normalizadora", coloca Foucault (1999a, p. 135), "é o efeito histórico de uma tecnologia de poder centrada na vida".

Na esteira dessas operações políticas, o sexo se encontra na interseção entre as disciplinas do corpo (adestramento, intensificação e distribuição das forças, ajustamento e economia das energias) e a regulação das populações. Foi inaugurada a temporada de vigilância, exames médicos e psicológicos, de uma microfísica do poder sobre o corpo; ademais, deu-se margem às medidas e estatísticas que tomaram grupos sociais para análise. De tal modo, a sexualidade foi dissecada no século XIX com "quatro grandes linhas de ataque ao longo das quais a política do sexo avançou nos últimos dois séculos" (FOUCAULT, 1999a, p. 137). As duas primeiras, de natureza reguladora, se apoiaram numa temática de saúde coletiva: sexualização da criança e a histerização das mulheres. As outras duas, cujo caráter era o de adestramento individual, se ocuparam do controle da natalidade e psiquiatrização das perversões. Em suma, o sexo uniu corpo e população para a gestão da vida.

Ao refletir sobre os efeitos do biopoder na atualidade, Preciado (2008) propõe uma atualização do conceito foucaultiano. Em sua perspectiva, os olhares precisam se voltar às formas de controle dos corpos e subjetividades que são exercidas por indústrias farmacêuticas, meios de comunicação e fluxos digitais. Em um primeiro momento, o autor argumenta que vivemos na "sociedade de controle" mencionada por Gilles Deleuze como uma nova forma de organização social pósSegunda Guerra Mundial, a qual veio por substituir a sociedade disciplinar, e seus mecanismos de poder são presentes, invisíveis e dispersos como um gás. Em seguida, pensando no modo como ciências e tecnologias conferem e compõem as vidas, destaca que Donna Haraway preferiu o conceito de "tecnobiopoder". Nesse sentido, Preciado afirma que já não se trata do poder de administrar a vida e a morte, conforme propõe Foucault, mas do controle exercido sobre um "complexo tecnovivo conectado". Não há um poder exterior que reside fora do corpo, mas poderes que habitam nossos corpos: medicamentos, métodos contraceptivos, próteses etc. Por isso, acredita ser necessário compensar o conceito de biopoder com o de potentia de Espinoza, porque os corpos dissidentes estão longe de serem dóceis uma vez que criam possibilidades de escape também dissidentes.

Assim como o dispositivo da sexualidade, o conceito de biopoder formulado por Foucault (1999a) forneceu ideias centrais à teoria queer para o estudo da gestão político-técnico-científica do corpo, da vida e da morte. Como demonstra Preciado (2008), o gênero, antes mesmo de se tornar uma reivindicação feminista, foi uma tecnologia médica utilizada para administração de corpos intersexuais e transgêneros.

Outro exemplo está nas ações do biopoder durante a emergência e condução das políticas de saúde para HIV/aids. Pelúcio e Miskolci (2009), inspirados em Néstor Perlongher, problematizam as políticas públicas de saúde para contenção de HIV/aids no Brasil. Para os autores, essa "estatização do biológico", ao lidar de forma preconceituosa no início da epidemia, lançou as bases do dispositivo da aids. Um dispositivo que opera por meio de políticas públicas de prevenção ao HIV controlando e normalizando as relações afetivas e sexuais segundo padrões heteronormativos, bem como produzindo subjetividades marcadas pela impureza e pela culpa. 


\section{Judith Butler \\ Atos performativos de gênero}

Em 1990, Judith Butler publicou Gender trouble: feminism and the subversion of identity, nos Estados Unidos. A tradução chegou ao Brasil somente em 2003, com o título Problemas de gênero: feminismo e subversão da identidade. Logo no Prefácio, a filósofa esclarece que, em sua abordagem, um "problema" precisa ser entendido não como algo negativo, mas como algo a ser compreendido em virtude de suas consequências. O grande problema a que a autora se refere é o das políticas de identidade presentes em discussões acerca do conceito de gênero no movimento social e na pesquisa feminista. Dessa maneira, a tese de que os discursos de gênero - na biologia, no estruturalismo, na psicanálise ou no feminismo - produziram a sua naturalização se coloca como central.

Analiticamente, Butler se aproximou da "genealogia do poder" praticada por Foucault (1999a; 1999b) para "explicar as categorias fundacionais de sexo, gênero e desejo como efeitos de uma formação específica de poder" (BUTLER, 2003, p. 9). Isso demandou direcionar o olhar para a função dual do poder: jurídica e produtiva. Pois, segundo a abordagem foucaultiana, os sistemas jurídicos geram os sujeitos que subsequentemente passam a representar, ou seja, sujeitos formatados de acordo com as exigências dessas estruturas. Ademais, a legitimação e exclusão são operações políticas que já estão ocultas e naturalizadas na própria análise política que as toma como fundamento. Em outras palavras, Butler se interessa pelas operações de podersaber e as exclusões que a busca de uma identidade comum no feminismo estaria impondo às existências que não correspondessem ao esperado.

Somado à genealogia, o conceito de "suplementaridade" e a abordagem metodológica da "desconstrução", do filósofo Jacques Derrida, são ferramentas centrais para Butler (2003). Com essa operação, seu objetivo foi tornar visível as práticas políticas que estão ocultas e que produzem sujeitos a partir dela. A "suplementaridade" mostra que significados são organizados por meio de diferenças em uma dinâmica de presença e ausência, ou seja, o que parece estar fora de um sistema já está dentro dele e o que parece natural é histórico (DERRIDA, 1973). Nessa perspectiva, por exemplo, a heterossexualidade precisa da homossexualidade para sua própria definição (MISKOLCl, 2009). Já a "desconstrução" pode ser entendida como um procedimento analítico que mostra o implícito dentro de uma oposição binária, a qual carrega carga semântica e tem como objetivo questionar a estrutura interna dos discursos, com a finalidade de acusar aquilo que os sintomas dos enunciados acobertam (DERRIDA, 1973).

Com tais procedimentos, Butler buscou desconstruir as estruturas binárias e normativas às quais o movimento feminista se agarrou desde o seu início: sexo/gênero e natureza/cultura. Em outras palavras, a autora argumenta que o sexo passou a ser apreendido como natural e o gênero como socialmente construído - consequentemente. Mas, a seu ver, a construção de 'homens' não diria respeito a corpos excepcionalmente masculinos ou 'mulheres' a corpos femininos. Do mesmo modo, questiona o fato de sexo e gênero serem apenas dois. Logo, os discursos estariam criando e circulando certos ideais de gênero e os tomando como essências naturais ou verdades internas que são subsequentemente expressadas nos ideais.

Pensando a esse respeito, a filósofa propõe que o gênero seja produzido discursivamente a partir das relações de poder e, especificamente, em meio às restrições normativas que produzem e regulam os corpos. Se o sexo não causa o gênero, então o gênero também não pode ser entendido como expressão ou reflexo do sexo. Conclui que se trata da repetição dos discursos e das normas que produzem e estabilizam os efeitos do gênero, bem como a materialidade do sexo.

Em diálogo com a historiadora Joan Scott, Butler menciona que a noção de pessoa é deslocada em razão do contexto social e histórico. Trata-se de algo inconstante e relativo. Do mesmo modo, gênero também precisa ser apreendido como transitório, relacional e contextual. Em contraposição a essa fluidez, os discursos de gênero agem sobre o sujeito em busca de uma coerência culturalmente estabelecida para atribuir humanidade. Em nossas sociedades, por exemplo, um bebê torna-se ser humano a partir do momento em que a pergunta 'menino ou menina?' é respondida. Sendo assim, gênero constitui-se como um qualificador dos corpos humanos.

Em suma, se gênero é um efeito que advém de práticas discursivas, então, está aberto a intervenções e ressignificações. Portanto, "gênero é performativo". Nas palavras da filósofa:

o gênero não é um substantivo, mas tampouco é um conjunto de atributos flutuantes, pois vimos que seu efeito substantivo é performativamente produzido e imposto pelas práticas reguladoras da coerência do gênero. Consequentemente, o gênero mostra ser performativo no interior do discurso herdado da metafísica da substância - isto é, constituinte da identidade que supostamente é. Nesse sentido, o gênero é sempre um feito, ainda que não seja obra de um sujeito tido como preexistente à obra (BUTLER, 2003, p. 48, grifos da autora). 
É possível observar que Butler concorda com Foucault ao enfatizar que os discursos constituem e habitam os corpos. Nesse sentido, a filósofa destaca os termos 'generificados' presentes na linguagem e propõe considerar gênero como ação, o que sugere uma construção dramática e repleta de sentidos. Tais atos são ao mesmo tempo novas experiências, um conjunto de significados socialmente estabelecidos e formas sociais de legitimação. Sendo assim, gênero não é uma identidade estável, mas constituído ao longo do tempo por uma repetição de atos (envolvendo falas, textos, comportamentos etc.) que resultam em naturalização. Atos que são, por sua vez, descontínuos, e que têm como efeito a produção de corpos que buscam a ilusão de um eu permanente marcado pelo gênero.

Cabe esclarecer alguns pontos quanto à performatividade de gênero elaborada por Butler (2003). É preciso pensar a performatividade de gênero, sobretudo, em termos de linguagem, como grande moduladora dos modos de ser e agir dos sujeitos através de termos 'generificados' presentes na linguagem. Embora Butler não dispense a possibilidade de escolha de gênero, ela sublinha que essa ação seria muito posterior ao processo de performatividade. Isto é, a performance seria posterior à performatividade.

Segundo Preciado (2008, p. 86, tradução minha), em Butler gênero está longe de ser uma "essência" ou uma "verdade psicológica", mas é pensado como "uma prática discursiva, corporal e performativa por meio da qual o sujeito adquire inteligibilidade social e reconhecimento político". O queer se localiza justamente no rompimento dos fluxos performativos cis-heteronormativos. Nesse sentido, a "performatividade queer" seria como um "tráfico de ficções por meio do qual certos enunciados de gênero são extirpados da autoridade do discurso médico (até mesmo no próprio momento de sua intervenção) e usados por um novo sujeito de conhecimento que agora reclama para si o status de 'especialista'" (PRECIADO, 2008, p. 276, tradução minha).

No entanto, Preciado questiona o fato de a teoria queer frequentemente se reduzir ao conceito butleriano. Para ele, há algo além à performatividade e à performance, algo que está na esfera biológica e também dos afetos. É justamente por isso que se interessa no gênero como um princípio organizador que leva ao surgimento de técnicas, saberes e instituições, e prefere, então, examinar a produção performativa nos níveis mais profundos do corpo, como os órgãos, as células, os genes, o desejo.

\section{A matriz heterossexual e os corpos abjetos}

Butler (2003, p. 215-216) chamou de "matriz heterossexual" a malha específica de poder que designa "a grade de inteligibilidade cultural por meio da qual os corpos, gêneros e desejos são naturalizados". Este, por sua vez, trata-se de um modelo performativo e epistemológico hegemônico que requer a estabilidade e a coerência entre sexo, gênero e desejo por meio da prática compulsória da heterossexualidade. Para a sua manutenção, a matriz regulatória opera com a produção de identidades (sexuais e de gênero) a serem reafirmadas cotidianamente. Em outros termos, um homem deve atender aos padrões de masculinidade, possuir um pênis e desejar exclusivamente corpos de mulheres.

Há, no entanto, escapes à conformação identitária, bem como pode haver ruídos em processos de comunicação. Emergem daí práticas e existências que transbordam as fronteiras da malha de poder heterocentrada, isto é, aquelas em que gênero não decorre do sexo e cujo desejo não decorre nem do sexo nem do gênero. Nesse contexto, o ato de "decorrer", conforme Butler, é a imposição de uma relação política que regula a sexualidade.

Em diálogo com Foucault (1999a), Butler defende que, assim como gênero e sexo, o desejo também pode ser entendido como efeito de práticas discursivas, portanto, linguisticamente elaborado. A entrada de um bebê no campo cultural (discursivo), por exemplo, desloca as expectativas em torno de seu desejo. Isto é, ocorrem pressuposições e sanções acerca do que seria legítimo ou não para o seu desejo na relação com o seu sexo e, concomitantemente, o gênero. Além disso, a autora afirma que os modos de prazer centrados no pênis, na vagina e nos seios também "correspondem a um ideal normativo de um corpo já portado de um gênero específico" (BUTLER, 2003, p. 108).

A partir da antropóloga Esther Newton, Butler sugere que travestis e drag queens são os rastros empíricos que subvertem o modelo de (identidade de) gênero postulado como verdadeiro ao mesmo tempo que afirmam descontinuidades entre prazeres sexuais e partes corporais. A drag queen apresenta uma dissonância entre sexo e performance, e também entre sexo e gênero, e entre gênero e performance. A travesti, embora represente a imagem de uma mulher, também desloca aspectos de gênero falsamente naturalizados por meio de regulações heterossexuais.

Para pensar as cisões e os efeitos da matriz heterossexual, Butler recupera criticamente a discussão de Foucault sobre os diários de Herculine Barbin em História da sexualidade 1. Para ela, ao "romancear" as experiências hermafrodita ou intersexuada nas narrativas autobiográficas de Herculine, contradições emergem em Foucault, uma vez que o filósofo "deixa de reconhecer as relações de poder concretas que tanto constroem como condenam a sexualidade de Herculine" 
(BUTLER, 2003, p. 140). Herculine atestaria, segundo Foucault, uma feliz possibilidade de existência que ultrapassa as categorias do sexo e da identidade. Embora concorde que os prazeres de Herculine transcendam a regulação ora imposta, Butler sublinha que, ao postular a possibilidade de uma sexualidade "antes da lei", Foucault contradiz a sua tese central de uma sexualidade "posterior à lei". Contudo, mesmo "fora da lei", Herculine é regulada porque a lei abrange este "fora" que constrói a própria noção de natureza. Em suma, os relatos de Herculine sobre as suas experiências corporais, afetivas e sexuais não permitem enquadramentos binários de sexo/gênero/ desejo e conformações identitárias.

A anatomia de Herculine não fica fora das categorias do sexo, mas confunde e redistribui seus elementos constitutivos; na verdade, a livre interação dos atributos tem o efeito de denunciar o caráter ilusório do sexo como substrato substantivo permanente ao qual esses vários atributos devem presumivelmente aderir. Além disso, a sexualidade de Herculine constitui um conjunto de transgressões de gênero que desafia a própria distinção entre as trocas eróticas heterossexuais e lésbicas, subestimando seus pontos de convergência e redistribuição ambíguas (BUTLER, 2003, p. 149).

Considerando o corpo como central para a compreensão das operações da matriz heterossexual, Butler o abordará em dois movimentos - discussão que desenvolve, especialmente, na relação com Foucault, Mary Douglas, Lacan e Julia Kristeva. Em um primeiro momento, a filósofa critica o fato de que mesmo em Foucault "o corpo é apresentado como superfície e cenário de uma inscrição cultural" (BUTLER, 2003, p. 186), fruto de uma história essencial e repressora. Para Foucault, assim como para Nietzsche, "os valores culturais surgem como resultado de uma inscrição no corpo, o qual é compreendido como um meio, uma página em branco" (BUTLER, 2003, p. 187).

Em um segundo momento, passa a delinear o conceito de "corpo abjeto", a partir da leitura do livro Policing desire: aids, pornography, and the media, de Simon Watney, no qual pensa a respeito de um "corpo poluidor gay" produzido por um conjunto de discursos midiáticos. De um lado, a aids é apresentada como a "doença gay". De outro, a "pessoa poluidora" seria aquela portadora de aids. De tal modo, o fato de a doença ser transmitida pela troca de fluidos corporais sugere os perigos que as fronteiras corporais permeáveis representam para a ordem social como tal.

A esse respeito, Butler recupera a tese da antropóloga Mary Douglas (1969) em Purity and danger, para quem o corpo estaria além do orgânico, podendo representar qualquer sistema delimitado cujas fronteiras são permeáveis. Mais especificamente, a autora se interessa por um problema colocado por Douglas que, a seu ver, seria de se esperar em Foucault: "Por que pensar que as fronteiras corporais são especificamente investidas de poder e perigo?" (BUTLER, 2003, p. 189). Inspirada nessa discussão, argumenta que

os ritos de passagem que governam os vários orifícios corporais pressupõem uma construção heterossexual da troca, das posições e das possibilidades eróticas marcadas pelo gênero. A desregulação dessas trocas rompe, consequentemente, as próprias fronteiras que determinam o que deve ser um corpo (BUTLER, 2003, p. 190).

Sendo assim, o corpo tecido pelo performativo não impõe um status ontológico que o separa, pelo contrário, o emaranha aos múltiplos atos que constituem a sua realidade. Destaca daí o interesse da filósofa pelos corpos que escapam à matriz heterossexual, que ficam fora do entendimento de humano e constituem o domínio do "abjeto".

O "abjeto" designa aquilo que foi expelido do corpo, descartado como excremento, tornado literalmente "Outro". Parece uma expulsão de elementos estranhos, mas é precisamente através dessa expulsão que o estranho se estabelece. A construção do "não eu" como abjeto estabelece as fronteiras do corpo, que são também os primeiros contornos do sujeito (BUTLER, 2003, p. 190-191).

Portanto, de acordo com Butler (2003, p. 198), "o corpo não é um 'ser', mas uma fronteira variável, uma superfície cuja permeabilidade é politicamente regulada, uma prática significante dentro de um campo cultural de hierarquia do gênero e heterossexualidade compulsória". De tal modo, o corpo é uma matéria constituída de forma intimamente relacionada ao contexto sociopolítico em que vive. É de interesse da matriz heterossexual o estímulo à produção de seres abjetos para a sua sustentabilidade. Afinal, para que exista um ideal de normalidade faz-se necessária a produção de seus contrastes complementares, que sejam fabricadas noções de anormalidade e corpos que a sustentem. Nesse sentido, o corpo abjeto é uma sujeição social, além de um componente do processo de subjetivação. É nesse contexto que o abjeto diz respeito àquelas vidas que não são consideradas vidas e cuja materialidade é tida como sem importância, embora necessária para a manutenção da matriz regulatória.

Os conceitos aqui trabalhados ofereceram à teoria queer uma rica discussão para pensar a produção de corpos, gêneros, sexualidades e experiências abjetas dentro da matriz 
heterossexual. A pesquisa de Berenice Bento (2006) sobre sexualidade e gênero na experiência transexual pode ser recuperada neste momento. Como nos mostra Bento, essas vidas apresentam o caráter inconclusivo dos corpos, que são desfeitos e refeitos. São corpos que diluem quaisquer fronteiras entre o natural e o artificial, entre o real e 0 fictício. Para a autora, as experiências transexuais questionam a matriz que confere inteligibilidade aos gêneros e ao mesmo tempo sustenta tecnologias de saber-poder que buscam afirmar um/a "transexual verdadeiro/a". Então, dada a capacidade de criar fissuras nas normas de gênero e sentir os seus efeitos diretos, no lugar de pensar uma "identidade coletiva transexual", a autora sugere pensar em "comunidade de emoções".

Por fim, há um problema que parece não estar resolvido em Butler (2003): seria possível pensar a igualdade em meio às políticas de identidade que geram a exclusão? Preciado (2011) propõe como solução pensar as políticas das multidões queer, que questionam o caráter compulsório da heterossexualidade. Com Deleuze, argumenta que as cisões queer se colocam como processos de desterritorialização que afetam tanto o espaço urbano quanto o espaço corporal. São contranarrativas que resistem aos processos de "tornar-se normal". Não há passividade aqui, mas corpos que também podem intervir nas tecnologias de poder-saber a seu favor. São corpos que fazem dos desvios das biotecnologias e da transgressão aos imperativos do desejo novos modos de existência. Identificações estratégicas, portanto, são possíveis e necessárias.

Não existe diferença sexual, mas uma multidão de diferenças, uma transversalidade de relações de poder, uma diversidade de potências de vida. Essas diferenças não são "representáveis" porque são "monstruosas" e colocam em questão, por esse motivo, os regimes de representação política, mas também os sistemas de produção de saberes científicos dos "normais" (PRECIADO, 2011 , p. 18).

\section{Paul B. Preciado \\ Regime farmacopornográfico}

Paul B. Preciado levou às últimas consequências os efeitos das biotecnologias de gênero em seu corpo. Em Testo yonqui, publicado em 2008, na Espanha (no Brasil, a tradução foi publicada em 2018, com o título Testo junkie: sexo, drogas e biopolítica na era farmacopornográfica), conceitos são tensionados em conjunto com as sensações mobilizadas pelo autoexperimento com testosterona sintética (com duração de 236 dias e noites) filmado e compartilhado de forma anônima em uma página na internet sobre experiências trans. Nesses movimentos, as demarcações claras entre realidade e ficção são postas à prova. Não bem um livro, como ele sugere, mas um protocolo de intoxicações voluntárias, um ensaio corporal, uma ficção autopolítica, ou ainda, uma autoteoria.

Na escrita desse diário de micromutações fisiológico-políticas, o autor se alia à crítica feminista e à filosofia pós-estruturalista para apreender não apenas os processos de subjetivação e sujeição acerca do corpo, gênero e sexualidade, seus aspectos rizomáticos, mas também a potência de agir gestada na vida em contraposição às políticas de identidade. Como e por que o sexo e a sexualidade se converteram no centro da atividade política e econômica? De que maneira as identidades sexuais e de gênero se tornaram intragáveis? Quais seriam os modos de escapar às capturas políticas? Esses são problemas caros ao filósofo. Diferentemente do ensaiado por Foucault (1999a) e Butler (2003), nesse caso não há qualquer distanciamento entre aquele que produz e a própria obra.

Teria nascido com o capitalismo disciplinar, segundo Preciado (2008), uma "sexopolítica" para produção e controle dos sexos, prazeres, sexualidades, gêneros e corpos por meio de atos performativos. Dissecando a biopolítica, esta extrapola a regulação da reprodução da vida e o controle da população, porque edifica um verdadeiro "império sexual" que toma o sexo para inventar e controlar as subjetividades modernas.

Seguindo as pistas do dispositivo da sexualidade e expandindo as notas históricas para outros contextos, Preciado sublinha que desde o século XIX as forças políticas passaram a ditar modos de ser e de prazer. Por exemplo: em 1868 foi criada por Krafft-Ebing uma enciclopédia de identidades sexuais e de sexualidades normais e perversas e suas patologias; as leis de criminalização da sodomia se expandiram pela Europa; a diferença sexual foi legitimada tendo como base os órgãos sexuais e reprodutores, conferindo ao pênis a centralidade e a referência para a definição de uma identidade sexual; foram realizados os primeiros experimentos de inseminação artificial em animais; houve a intervenção no prazer feminino com a ajuda de objetos mecânicos e a medicalização do orgasmo como fonte de crise histérica; e se mecanizou e domesticou o orgasmo masculino por meio de uma produção pornográfica ainda incipiente.

Através dessas tecnologias, os órgãos reprodutores foram elevados à potência máxima. Mas o ânus - que não possui um gênero - produz um curto-circuito no regime político heterossexual, na divisão sexual e no capital, o que the confere o centro da passividade sexual, um lugar abjeto 
por excelência. Do mesmo modo, corpos que escapam às normas configuram monstruosidades. Práticas sexuais foram transformadas em identidades e condições políticas a serem estudadas, catalogadas, vigiadas, punidas, curadas. Assim, os dispositivos sexopolíticos disciplinares acompanharam uma nova estética da diferença sexual e das identidades sexuais que partem de técnicas de naturalização do sexo.

Considerando as transformações contemporâneas das tecnologias de produção de subjetividade na história da sexualidade, Preciado propõe a seguinte leitura: passamos da "sociedade disciplinar", sugerida por Foucault, para o "regime farmacopornográfico". Nesse novo regime, as fronteiras entre poder e subjetivação se tornaram borradas. As linhas de controle não mais atuam de fora dos corpos para dentro, mas de dentro do próprio indivíduo para fora. O "panóptico" - conceito desenvolvido por Foucault (1999b) para pensar os mecanismos de vigilância e controle modernos - assume a forma de pílulas, implantes subcutâneos, microchips. Logo, os binômios nocividade/cura e público/privado das pílulas, líquidos, moléculas, fluxos, assim como a atuação dessas substâncias sobre os corpos e a subjetividade são mais invisíveis e presentes nas vidas contemporâneas.

Embora o regime farmacopornográfico tenha passado a compor as experiências de vida de modo mais intenso e invisível a partir da segunda metade do século $X X$, as suas raízes são mais profundas. Com relação a isso, Preciado recupera as transformações da economia europeia medieval de finais do século XV em direção às economias industriais, aos Estados-Nação e aos regimes de saber técnico-científicos ocidentais. Rememorando períodos de inquisição, o autor percorre a condenação da bruxaria (ancorada na expropriação de saberes tradicionais e criminalização de práticas terapêuticas), a privatização de espécies vegetais, as técnicas de repressão da sexualidade das mulheres e do ato sexual não reprodutivo (como a sodomia e a masturbação), e a experimentação de substâncias psicoativas. Com essas linhas que compõem a 'trama da sexualidade', iniciou-se um processo de controle que entrelaça experimentações alucinógenas e sexuais. São aspectos que culminaram no tráfico de drogas, na condenação moral e política do uso de alucinógenos, nas patentes farmacológicas e no confisco de substâncias por instituições médico-jurídicas.

De acordo com Preciado, esse regime farmacopornográfico se sustentaria por meio de dois grandes poderes e suas técnicas de controle, aos quais não foi dedicada a devida atenção em Foucault e Butler: o "farmacopoder" e o "pornopoder".

Com o advento da Segunda Guerra Mundial, os hormônios se tornaram centrais ao farmacopoder. Todo o processo de descoberta e produção dos hormônios, afirma Preciado (2008), permite traçar uma "cartografia dos espaços sexopolíticos disciplinares" (p. 124) e compor um "arquivo farmacopolítico" (p. 150). Em outras palavras, é possível encontrar diferentes instituições de fornecimento, produção e controle da feminilidade e da masculinidade como técnicas de produção de gênero. Viagra e testosterona são as novas produções moleculares da masculinidade, por exemplo.

Para o filósofo, a categoria 'gênero' está distante de ser uma criação feminista dos anos 1960 - que ignorou a sua dimensão técnica -, mas se encontra nos braços do "farmacopoder". As noções tecnocientíficas de masculinidade e feminilidade que conhecemos hoje nasceram na Segunda Guerra Mundial e se expandiram com a Guerra Fria. Em 1947, o psicólogo e sexólogo Jonh Money passou a utilizar a categoria gênero para referir-se ao "sexo psicológico" nos processos de tratamento hormonal e cirúrgico dos corpos de bebês assinalados como intersexuais. Gênero emerge, sobretudo, como produzido, sintético, maleável, transferível e passível de reprodução.

Preciado destaca outro importante personagem nesta 'biografia farmacopolítica do gênero': o médico Harry Benjamin. Diferente de Money, Benjamin passou a administrar, na década de 1960, doses de estrógenos e testosterona em pacientes adultos que não se identificavam com o gênero que lhes fora designado. É nesse movimento que no período da Guerra Fria surge uma nova distinção ontológica-sexual (distinções que aparecem no final do século XX nos EUA e na Inglaterra): os homens e as mulheres que se identificam com o gênero designado, biohomem e bio-mulher (ou cis-homem/mulher), e aqueles que não se identificam, trans-homem e trans-mulher. Salienta ainda que ambos os estatutos de gênero bio/cis e trans são tecnicamente produzidos, porque dependem de métodos de reconhecimento visual, produção performativa e controle morfológico comuns.

Em diálogo com essa biografia farmacopolítica e com a leitura cinematográfica de produção da subjetividade realizada por Teresa De Lauretis, Preciado (2008, p. 83, tradução minha) entende gênero como "o efeito de um sistema de significação, de modos de produção e de decodificação de signos visuais e textuais politicamente regulados". Logo, gênero não se resume ao efeito de um sistema fechado de poder ou uma ideia que adere à matéria, mas é um efeito de práticas discursivas e visuais que emanam de diferentes dispositivos institucionais, como a família, a religião, a escola, as mídias, o aparato biomédico, jurídico e até mesmo do cinema. Além disso, em seu entendimento, gênero não é um simples derivado do sexo (anatômico ou 
biológico), uma vez que existe a possibilidade de produzi-lo em escala molecular. O sujeito, nesse processo, está imbricado à representação, significação e autoexperimentação corporal.

A partir de De Lauretis, Butler e Haraway, o filósofo se interessa pela dimensão semióticotécnica dessa produção performativa, pela ecologia política de gênero. De tal modo, prefere pensar em "tecnogênero" para "dar conta do conjunto de técnicas fotográficas, biotecnológicas, cirúrgicas, farmacológicas, cinematográficas ou cibernéticas que constituem, performativamente, a materialidade dos sexos" (PRECIADO, 2008, p. 86, tradução minha).

Em suma, o farmacopoder diz respeito: aos modos de controle médico, jurídico, político e moral dos fármacos para obtenção de lucro e gestão de populações; à penetração dos fármacos na vida cotidiana e na transformação dos corpos, das subjetividades, dos gêneros e das sexualidades; e ao crescimento do tráfico de substâncias como resistência a essas condições. Mas, além desse poder, há ainda o outro braço do regime farmacopornográfico: o "pornopoder".

De acordo com Preciado, a pornografia é uma tecnologia central ao pornopoder. Esta, por sua vez, reúne uma série de dispositivos, atos performativos e performances que se configuram através de suportes audiovisuais. É um dispositivo virtual (literário, audiovisual, cibernético) masturbatório, cujas imagens têm a capacidade de estimular os mecanismos bioquímicos e musculares que regem a produção de prazer do espectador. Ao mesmo tempo, a pornografia faz da sexualidade um espetáculo comercializável digitalmente, um dispositivo de publicitação do privado. Diante da necessidade de produção que obedeça à velocidade do mercado (em criação e atendimento às demandas), exige preocupações estéticas, políticas e narrativas contendo técnicas de reprodução sexual que resultam mais da cenografia, teatralização e de iluminação do que de conteúdo. No espetáculo do sexo, a ejaculação é tida como verdade e tudo gira em torno desse fim.

Nesse sentido, a pornografia retrata a verdade sobre a sexualidade porque a apresenta como performance, uma representação, e também como um mecanismo involuntário de conexão ao circuito global de excitação-frustração-excitação. Então, o que movimenta esse mercado são os modos de controle visual, bioquímico, afetivo, performático e a dificuldade em conceder prazer a si mesmo ou a outro corpo. O que Preciado nos mostra é que no pornopoder os mecanismos de controle da excitação transbordam para a vida cotidiana que se faz multimídia e conectada. Vivemos em sociedades que controlam (por meio de eletrônicos, textos, telas, áudios, vídeos etc.) o desejo através de uma "satisfação frustrante". Dentro dos padrões cis-heteronormativos e coloniais, há sempre algo novo e melhor a ser consumido, como bens materiais, medicamentos, relações afetivas e sexuais, suplementos corporais, e assim por diante.

Para Preciado, seria até mesmo possível pensar em uma nova ciência social, denominada "farmacopornologia", que se volte aos

processos de produção, distribuição e consumos de bens e serviços farmacopornográficos, assim como o comportamento dos seres tecnovivos como uma relação entre determinados fins (excitação, orgasmo, relaxamento etc.) e meios escassos (drogas psicotrópicas, dados audiovisuais, práticas etc.) (PRECIADO, 2008, p. 208, tradução minha).

Se antes corpo, desejo, sexo e gênero eram pensados como substâncias da natureza, propriedade de Deus, propriedade do Estado e propriedade privada, hoje, são tomados como propriedade das grandes multinacionais farmacopornográficas. Passamos da condenação da masturbação ao seu aproveitamento pela pornografia, como controle de reprodução sexual e pelas técnicas de inseminação artificial. Trata-se de um regime que controla a relação entre seres vivos, coisas, afetos, prazeres, drogas, conteúdo audiovisual e comportamentos. Com a participação voluntária e cotidiana, a divisão público/privado veio a baixo. O corpo, portanto, é uma multidão.

Antes de passar ao último conceito que gostaria de me dedicar em Preciado, considero pertinente trazer algumas críticas de Pelúcio (2014) e Pereira (2012) dirigidas ao filósofo. Para Pelúcio (2014), há algo de colonial e paradoxalmente androcêntrico em Testo yonqui. A segunda crítica não é desenvolvida pela autora. Com relação à primeira, Pelúcio parece preocupar-se com a absorção nacional de seus conceitos sem "torcê-los", ou seja, encará-los com a devida crítica latino-americana. Embora saiba falar e escrever em três idiomas, coloca a autora, Preciado não incorpora em seus trabalhos os saberes produzidos no "cu do mundo", assim como também não o fez Foucault. Sugere, então, uma "teoria $\mathrm{cu}^{\prime}$ que dê a ver nossos saberes cucarachas, subalternos, pois "o cu excita na mesma medida em que repele, por isso é queer" (PELÚClO, 2014, p. 10). Segundo Pelúcio, há grande originalidade em nossa produção antropofágica e sintonizada na produção marginal, afrontosa, no "cu depreciado".

Para Pereira (2012), é preciso considerar que falamos de um filósofo cuja obra está a ser experimentada e em processo de desenvolvimento. Mas, assim como Pelúcio, considera delicada a sua pretensão universalizante desde o "norte global". Um universal que se propõe a pensar as condições de emergência do biopoder no ocidente, mas esquece ou apenas tangencia ações 
coloniais. A seu ver, o filósofo que fala de grandes cidades da Europa e Estados Unidos não alcança as experiências de corpos queer no Brasil.

As leituras de Pelúcio e Pereira abrem novas inflexões, mas ainda carecem de apontamentos mais detidos às complexas formulações conceituais de Preciado. Afinal, quão distante as nossas estéticas e existências estão das tecnociências estadunidenses e europeias? Esse problema é central em Preciado. São encontros que não oferecem soluções, mas ricos problemas a serem experimentados antropofagicamente por e com multidões queer de muitos Brasis.

\section{Da potentia gaudendi}

Por fim, gostaria de reter um conceito formulado por Preciado (2008) durante as reflexões sobre o regime farmacopornográfico: o de "potentia gaudendi". O conceito busca aglutinar ideias sobre como e por que a força do corpo, corpo excitável, culminou no centro da ação política até chegar a ser objeto de uma gestão molecular.

A potentia (potência de atuar ou força de existir) advém da noção grega de dynamis, recuperado da interpretação de Deleuze em seu curso sobre Espinoza. A partir disso, Preciado (2008) chama de "potentia gaudendi" ou "força orgásmica" a "potência (presencial ou virtual) de excitação (†otal) de um corpo" (p. 38, tradução minha). É uma potência cuja capacidade é indeterminada, que não tem gênero, não é humana nem animal, hetero ou homo, não diferencia sujeito de objeto. Um pênis não tem mais força orgásmica que a vagina, o olho ou o dedo. É uma soma de excitação de cada molécula viva. Essa força orgásmica reúne ao mesmo tempo alma, força psíquica, somática e bioquímica. Por isso, só existe como relação, prática e devir. Ela não é só permanente e altamente maleável, mas, sobretudo, impossível de ser possuída e conservada. Portanto, não pode ser reduzida ou transformada em propriedade privada.

Uma vez que a potentia gaudendi é ao mesmo tempo abstrata e material, carnal e digital, passível de quantificação, mas incapturável, o regime farmacopornográfico busca produzir uma força de trabalho orgásmica abstrata, seja na forma de fármacos, aplicativos, representação pornográfica ou serviços afetivo-sexuais. Isso constitui o grande alimento desse novo regime com capacidade de nutrir as engrenagens capitalistas. Se no século XIX a masturbação foi condenada, agora, ela passa a ser aproveitada por meio da pornografia, como controle de reprodução sexual e pelas técnicas de inseminação artificial.

Nesse sentido, todo corpo, mesmo um corpo "morto", pode despertar força orgásmica e, portanto, ser portador do poder de produção do capital sexual. Essa força que se permite converter-se em capital não reside no bíos, tal como é entendido de Aristóteles a Darwin, mas na tecnoeros, no corpo tecnovivo encantado e sua cibernética amorosa. Daí a conclusão: tanto a biopolítica (política de controle e produção da vida) como a necropolítica (política de controle e gestão da morte) funcionam como farmacopornopolíticas, gestões planetárias da potentia gaudendi (PRECIADO, 2008, p. 40, grifos do autor, tradução minha).

Então, uma vez que o corpo não se reduz ao pré-discursivo, tampouco termina na pele, a potentia gaudendi não pode ser entendida como um mero fato biológico. Isso porque o corpo só se constitui na relação com a produção de materiais e fluxos tecnocientíficos (microchips, genes, modelagem 3D, órgãos artificiais etc.). Preciado (2008) sustenta conceitualmente um corpo multiconectado que borra as fronteiras entre arte, natureza, ciência e tecnologia, um "tecnocorpo".

Todavia, para o filósofo, não existe relação ontológica entre anatomia e potentia gaudendi. No contexto farmacopornográfico, há um novo sujeito hegemônico: um corpo (ora codificado como masculino, branco, heterossexual) farmacopornograficamente suplementado (por drogas, pornografia) e consumidor de serviços sexuais pauperizados (muitas vezes exercidos por corpos codificados como femininos, infantis, racializados). Aqui, o que importa é o conjunto de representações que transformam um corpo em sexual e desejável.

Preciado recorre ao conceito de "vida nua" de Agamben (a partir de W. Benjamin) pósAuschwitz, onde fora negado ao sujeito aparo jurídico e cidadania, para pensar em "vidas farmacopornográficas", cujos corpos são utilizados como fonte de produção de potentia gaudendi. Estes seriam corpos-fontes carnais e numéricos de capital ejaculante, como qquelas/es que se entregam à prostituição ou à indústria pornográfica. Afinal, vivemos em um "laboratório-bordel global integrado multimídia" (PRECIADO, 2008, p. 44, grifos do autor, tradução minha). Haveria, por outro lado, os "biocorpos precários" (p. 46), que não produzem benefícios ejaculantes. Essas são as pessoas vivendo com HIV/aids em situação de vulnerabilidade, sem acesso ao tratamento, por exemplo. Desejo sexual e enfermidade coexistem nesse regime com suportes técnicos, farmacêuticos e midiáticos capazes de gestá-los.

Mesmo que imersos nos invisíveis mecanismos de controle do regime farmacopornográfico, para Preciado (2008), escapes às capturas tecnopolíticas são possíveis. Isto porque o corpo não se resume a uma prótese política viva, com capacidade total e abstrata voltada para criar prazer a serviço da produção capitalista. O corpo não é dócil, como descrito por Foucault (1999b). O 
corpo reúne, antes de tudo, uma potência de vida cara à teoria queer. Em outras palavras, falar em corpo requer pensar nos criativos modos de resistência produzidos em contraposição aos fluxos de controle contemporâneos.

\section{Consideraçōes finais}

Em uma reflexão sobre os saberes queer, Gayle Rubin (2016) menciona o desejo de novas gerações em 'reinventar a roda' nas pesquisas de gênero e sexualidade. No entanto, os estudos queer são feitos de camadas, lembra a autora, cujos saberes subversivos não respeitam as limitações disciplinares. Então, caberia às novas gerações o esforço geológico de escavação, catalogação e preservação dessas camadas de produção acadêmica em direção a novas problematizações e avanços na produção do conhecimento.

Este artigo de revisão reúne um esforço geológico de minha parte. Para o seu desenvolvimento, revisei ideias principais de Foucault (1999a), Butler (2003) e Preciado (2008), consideradas centrais ao desenvolvimento da teoria queer. São obras que compõem a minha trajetória nos estudos de gênero e sexualidade e que, de forma mais ampla, também exprimem o meu interesse em pensar uma antropologia centrada nos modos de existência em sua multiplicidade.

Nesse sentido, a teoria queer foi pensada como um conjunto de encontros entre pensamentos em constante reinvenção. Derivaram desses diálogos tessituras de conceitos e operações analíticas com disposição política, cujas forças residem em suas habilidades de afrouxar ou até mesmo desatar os nós de verdades cis-heterocentradas, especialmente, no que diz respeito a corpos, gêneros e sexualidades.

Entre controles, resistências e (auto)experimentações criativas, foi possível atentar para o corpo como um laboratório político por excelência. Corpo este que não está encerrado em si mesmo, fechado às contaminações externas, mas que é aberto, plástico, produzido e reinventado diariamente. Nesse processo, os atos performativos de gênero e sexualidade mobilizam uma complexa teia de discursos e instituições que constituem sujeitos e processos de sujeição. Existências e afetos são fragmentados, organizados e gerenciados mediante uma lógica cis-heteronormativa que dita os modos de viver e morrer.

Conforme discutido, a teoria queer oferece um rico conjunto de reflexões e práticas metodológicas para pensar criticamente a produção e as estratégias de contenção das diferenças, assim como a sua potência de transformação. Ao buscar dar a ver as aproximações e os distanciamentos entre as propostas aqui recuperadas, também houve o esforço de tornar mais acessíveis as suas formulações conceituais e operações analíticas. Esta não se trata de uma abordagem conclusiva, mas um convite a leituras mais detidas e que arrisquem outros intensos encontros.

\section{Referências}

AHMED, Sara. "Entrevista - Judith Butler: 'Boa parte de teoria queer foi dirigida contra o policiamento da identidade'", Revista ComCiência, v. 1, n. 185, 2017. Disponível em http://www.comciencia.br/ entrevista-com-judith-butler/. Acesso em 21/04/2020.

BENTO, Berenice. A reinvenção do corpo: sexualidade e gênero na experiência transexual. Rio de Janeiro: Garamond, 2006.

BUTLER, Judith. Problemas de gênero: feminismo e subversão da identidade. Rio de Janeiro: Civilização Brasileira, 2003.

CARRILLO, Jesús. "Entrevista com Beatriz Preciado". Cadernos Pagu, Campinas, n. 28, p. $375-$ 405, jun. 2007. Disponível em https://doi.org/10.1590/S0104-83332007000100016. Acesso em $21 / 04 / 2020$.

CÓRDOBA, David, SÁEZ, Javier; VIDARTE, Paco. Teoria queer. políticas bolleras, maricas, trans, mestizas. 2. ed. Madrid: Editorial Egales, 2007.

De Lauretis, Teresa. "Queer theory: lesbian and gay sexualities: an introduction". Differences, Providence, v. 3, n. 2, p. 3-28, 1991.

DERRIDA, Jacques. Gramatologia. São Paulo: Perspectiva, 1973.

DOUGLAS, Mary. Purity and danger. London; Boston; Henley: Routledge e Kegan Paul, 1969.

FOUCAULT, Michel. História da sexualidade 1: a vontade de saber. 13. ed. Rio de Janeiro: Graal, 1999a. 
FOUCAULT, Michel. Vigiar e punir: nascimento da prisão. 20. ed. Petrópolis: Vozes, 1999b.

HALPERIN, David. "The normalization of queer theory". Journal of Homosexuality, New York, EUA, v. 45, n. 2/3/4, p. 339-343, Feb. 2003. Disponível em https://doi.org/10.1300/J082v45n02_17. Acesso em 19/08/2019.

LOURO, Guacira Lopes. "Os estudos queer e a educação no Brasil: articulações, tensões, resistências". Contemporânea, São Carlos, v. 2, n. 2, p. 363-369, 2012. Disponível em http://www. contemporanea.ufscar.br/index.php/contemporanea/article/view/87. Acesso em 19/08/2019.

LOURO, Guacira Lopes. "Teoria queer: uma política pós-identitária para a educação". Revista Estudos Feministas, Florianópolis, v. 9, n. 2, p. 541-553, 2001. Disponível em https://doi.org/10.1590/ S0104-026X2001000200012. Acesso em 21/04/2020.

MISKOLCl, Richard. "A Teoria Queer e a Sociologia: o desafio de uma analítica da normalização". Sociologias, Porto Alegre, n. 21, p. 150-182, 2009. Disponível em http://www.scielo.br/scielo. php?pid=S1517-45222009000100008\&script=sci_abstract\&tIng=pt. Acesso em 19/08/2019.

MISKOLCl, Richard. "Estranhando as Ciências Sociais: notas introdutórias sobre Teoria Queer". Revista Florestan Fernandes, São Carlos, v. 1, n. 2, p. 8-25, 2014. Disponível em http://www.revistaflorestan. ufscar.br/index.php/Florestan/article/view/62. Acesso em 21/04/2020.

MISKOLCl, Richard. Teoria queer: um aprendizado pelas diferenças. Belo Horizonte: Autêntica, 2012.

ORLANDI, Luiz. Arrastões na imanência. Campinas: Editora Phi, 2018.

PELÚCIO, Larissa. "Traduções e torções ou o que se quer dizer quando dizemos queer no Brasil?", Periódicus, Salvador, v. 1, n. 1, p. 68-91, 2014. Disponível em https://portalseer.ufba.br/index.php/ revistaperiodicus/article/view/10150. Acesso em 19/08/2019.

PELÚCIO, Larissa; MISKOLCl, Richard. "A prevenção do desvio: o dispositivo da aids e a repatologização das sexualidades dissidentes". Sexualidad, Salud y Sociedad, Rio de Janeiro, n. 1, p. 125-157, 2009. Disponível em http://www.redalyc.org/articulo.oa?id=293322961007. Acesso em $19 / 08 / 2019$.

PEREIRA, Pedro Paulo. "Queer nos trópicos". Contemporânea - Revista de Sociologia da UFSCar, São Carlos, v. 2, n. 2, p. 371-394, jul./dez. 2012. Disponível em http://www.contemporanea.ufscar. br/index.php/contemporanea/article/view/88. Acesso em 02/05/2020.

PERLONGHER, Néstor. O negócio do michê: prostituição viril em São Paulo. São Paulo: Brasiliense, 1987.

PRECIADO, Paul B. "Multidões queer: notas para uma política dos 'anormais"'. Revista Estudos Feministas, Florianópolis, v. 19, n. 1, p. 11-20, abr. 2011. Disponível em https://periodicos.ufsc.br/ index.php/ref/article/view/S0104-026X201 1000100002/18390. Acesso em 30/04/2020.

PRECIADO, Paul B. Testo yonqui. Madrid: Espasa Calpe, 2008.

RUBIN, Gayle. "Geologias dos estudos queer: um déjà vu mais uma vez". Sociedade e Cultura Goiânia, v. 19, n. 2, p. 117-125, 2016. Disponível em https://www.revistas.ufg.br/fchf/article/ view/48676. Acesso em 19/08/2019.

Kris Herik de Oliveira (k162132@dac.unicamp.br) é doutorando em Ciências Sociais (IFCH/ Unicamp), mestre em Ciências Humanas e Sociais Aplicadas (FCA/Unicamp), bacharel em Ciências Sociais - Antropologia (IFCH/Unicamp) e Administração (CCSA/Mackenzie). Atua principalmente nos seguintes temas: modos de conhecimento e suas expressões, experiências e trajetórias, corpo, afetos, sexualidade, gênero e tecnociências. Atualmente, pesquisa as configurações e desdobramentos de terapias experimentais para a cura do HIV. 


\section{COMO CITAR ESSE ARTIGO DE ACORDO COM AS NORMAS DA REVISTA}

OLIVEIRA, Kris Herik de. "Intensos encontros: Michel Foucault, Judith Butler, Paul B. Preciado e a teoria queer". Revista Estudos Feministas, Florianópolis, v. 29, n. 1, e67637, 2021.

\section{CONTRIBUIÇĀO DE AUTORIA}

Não se aplica.

\section{FINANCIAMENTO}

O presente trabalho foi realizado com apoio da Coordenação de Aperfeiçoamento de Pessoal de Nível Superior - Brasil (CAPES) - Código de Financiamento 001.

\section{CONSENTIMENTO DE USO DE IMAGEM}

Não se aplica.

\section{APROVAÇĀO DE COMITÊ DE ÉTICA EM PESQUISA}

Não se aplica.

\section{CONFLITO DE INTERESSES}

Não se aplica.

\section{LICENÇA DE USO}

Este artigo está licenciado sob a Licença Creative Commons CC-BY 4.0 International. Com essa licença você pode compartilhar, adaptar, criar para qualquer fim, desde que atribua a autoria da obra.

\section{HISTÓRICO}

Recebido em 18/09/2019

Reapresentado em 03/05/2020

Reapresentado 01/06/2020

Aprovado em 18/06/2020 